\title{
Inhibition of human gall bladder mucus synthesis in patients undergoing cholecystectomy
}

\author{
M Rhodes, A Allen, R H Dowling, G Murphy, T W J Lennard
}

\begin{abstract}
Hypersection of gall bladder mucus is associated with gall stone formation in animal models. ${ }^{1}$ Aspirin inhibits both mucus synthesis and secretion, prevents gall stone formation in animals ${ }^{2}$ and reduces gall stone recurrence in man after dissolution therapy. ${ }^{3}$ Mucus biosynthesis in human gall bladder mucosal explants is inhibited by aspirin in vitro. ${ }^{4} \mathrm{We}$ have studied the effects of aspirin in vivo. Fifty five patients with functioning gall bladder and stones have been randomised, 27 to group 1 (aspirin EC $300 \mathrm{mg}$ once daily for seven days before cholecystectomy) and 28 to group 2 (controls). Gall bladder bile composition was analysed and mucus synthesis rates measured using ${ }^{3} \mathrm{H}$-glucosamine incorporation into mucosal explants cultured for 24 hours. ${ }^{4}$ Patient age, sex, and gall bladder histology were similar in both groups. There were no differences in stone composition, gall bladder bile calcium concentration, cholesterol saturation and cholesterol nucleation time. The mean ${ }^{3} \mathrm{H}$-glucosamine incorporation in aspirin treated patients was $1347 \mathrm{fmol} / \mathrm{g}$ wet weight as compared with $2008 \mathrm{fmol} / \mathrm{g}$ wet weight in controls (95\% confidence interval 222-1100, $\mathrm{p}<0.005$, unpaired $t$ test). This reduction in biosynthesis was associated with gall bladder bile mucus concentrations of 7.6 $\mathrm{mg} / \mathrm{ml}$ in patients and $7.1 \mathrm{mg} / \mathrm{ml}$ in controls (ns). Treatment with aspirin led to a significant reduction in mucus biosynthesis by the gall bladder mucosa. This action is consistent with a role for aspirin in the prevention of gall stones.
\end{abstract}

(Gut 1992; 33: 1113-1117)

The advent of laparoscopic cholecystectomy is making a dramatic impact on the management of symptomatic patients with gall bladder stones. Despite this, many patients are still being treated with alternative approaches to cholecystectomy (both open abdominal and laparoscopic) in which the stones are removed or dissolved, but the gall bladder is left in situ. These include oral bile acid treatment, ${ }^{5-7}$ contact gall stone dissolution with solvents such as methylterbutylether, ${ }^{8}$ extracorporeal shock wave lithotripsy (ESWL) $+1-$ adjuvant oral bile acids ${ }^{9-11}$ and percutaneous cholecystolithotomy. ${ }^{1213}$ A major disadvantage of all these approaches is that approximately $50 \%$ of the patients develop recurrent stones. ${ }^{1+18}$ As yet, there is no reliable way of preventing this recurrence but studies of the pathogenesis of recurrent stones are important as they may provide clues about primary gall stone formation.

At least three factors contribute to the development of both primary and recurrent cholesterol stones: (i) supersaturated bile in which the amount of cholesterol present exceeds the limits of thermodynamic equilibrium, ${ }^{19} 20$ (ii) stasis associated with gall bladder motor dysfunction ${ }^{2122}$ and (iii) abnormal nucleation of cholesterol crystals from the supersaturated bile because of an excess of promoters or a deficiency of inhibitors of crystallisation, or both. ${ }^{23}$ Several lines of evidence suggest that excess mucus glycoprotein synthesis by the gall bladder mucosa, and secretion into the gall bladder lumen may play an important role in the nucleation and trapping or immobilising of cholesterol crystals. ${ }^{24} 25$ First, in prairie dogs fed a lithogenic diet, increased mucus glycoprotein synthesis and secretion by the gall bladder mucosa antedate the appearance of crystals and stones.' Aspirin treatment, however, prevents this excess mucus glycoprotein production and the development of gall stones in this animal model. ${ }^{2}$ Second, during weight reduction, obese patients are at risk of developing microcrystals, microstones and gall stones but Broomfield and colleagues $^{26}$ showed that aspirin reduced this risk. Third, in a retrospective survey of patients in the British-Belgian post dissolution trial, Hood $e t a l^{3}$ found that regular non-steroidal anti inflammatory drug (NSAID) ingestion prevented gall stone recurrence.

The aim of the present investigation, therefore, was to extend these preliminary observations by studying, prospectively, the effect of preoperative oral enteric coated aspirin treatment on the composition of gall bladder bile and on the rate of mucus glycoprotein synthesis by explanted gall bladder mucosa from gall stone patients scheduled for elective open cholecystectomy.

\section{Methods}

\section{PATIENTS}

Patients awaiting elective open cholecystectomy for gall stones were recruited from three hospitals: the Royal Victoria Infirmary and the Freeman Hospital in Newcastle upon Tyne and Ashington Hospital in Northumberland. Patients with a non-functioning gall bladder, previous peptic ulceration, or hypersensitivity to aspirin were excluded from the trial. In addition, patients already taking long term non-steroidal antiinflammatory agents were excluded.

Seventy three patients were randomised into two groups, 37 to group 1 (aspirin treated) and 36 to group 2 (untreated controls). Patients in group 1 were given $300 \mathrm{mg}$ of enteric coated aspirin (aspirin EC) once daily for seven days before 
cholecystectomy and a further single $600 \mathrm{mg}$ dose two hours before surgery. Controls received no NSAIDs during the week before surgery.

The choice of aspirin dose was based on the known safety and efficacy of $300 \mathrm{mg}$ aspirin EC/ day while the decision to treat the patients for seven days before cholecystectomy was made to improve compliance and facilitate administration of the trial.

\section{ETHICAL CONSIDERATIONS}

Informed consent was obtained from each patient and ethical approval for the study was granted by both the Newcastle and Northumberland Ethical Committees.

\section{LABORATORY METHODS}

\section{MUCUS GLYCOPROTEIN BIOSYNTHESIS IN MUCOSAL} EXPLANTS

Mucosal explants of freshly excised gall bladder were grown for 24 hours in tissue culture. ${ }^{27}$ Glucosamine hydrochloride, D-[6- $\left.{ }^{3} \mathrm{H}(\mathrm{N})\right]$-, with a specific activity of $1110.0 \mathrm{GBq} / \mathrm{mmol}$, was used to label macromolecules. ${ }^{3} \mathrm{H}$-glucosamine was used at a concentration of $74 \mathrm{KBq} / \mathrm{ml}$ in the tissue culture medium. Total ${ }^{3} \mathrm{H}$-glucosamine incorporation into mucin was measured after removal of protein and low molecular weight radioactive material by papain digestion (72 hours) and exhaustive dialysis against distilled water (144 hours). Papain digestion is an effective method for isolation of mucus glycoprotein After digestion, dialysis removes protein and non-glycosylated regions of protein core, leaving behind non-dialysable, mucus glycoprotein. ${ }^{28}$

Glucosamine incorporation into the glycoprotein component of mucin was confirmed by fractionation on a caesium chloride density gradient $^{29}$ and by gel filtration on sepharose $4 \mathrm{~B}$. All radioactive mucin fractionated in a peak coincident with purified, papain digested human gall bladder mucin. Gall bladder mucosa, killed in liquid nitrogen was used as a control to check for non-specific interactions between the tissue and ${ }^{3} \mathrm{H}$-glucosamine.

\section{MUCUS GLYCOPROTEIN CONTENT OF GALL}

BLADDER BILE

Quantitation of mucus glycoprotein was undertaken using a modified 'Slotblot' technique. ${ }^{30}$ After blotting samples of bile onto nitrocellulose membranes, mucus glycoprotein was visualised using the periodic acid/Schiff reaction. ${ }^{31}$ Colour yeild was then measured using a scanning densitometer (Shimadzu, Japan). Results were compared with those obtained by measuring glycoprotein after purification of the mucin by the traditional method of fractionation on a caesium chloride density gradient and showed close correlation.

CHOLESTEROL

The cholesterol concentration in bile was measured using the enzymatic method first described by Roda ${ }^{32}$ and modified by Bolton. ${ }^{33}$
Briefly, this involved diluting samples of gall bladder bile obtained by needle puncture at laparotomy 1 in 10 with isopropanol and incubating the diluted sample with three enzymes. Sequential treatment of bile with catalase, cholesterol esterase and cholesterol oxidase (Sigma, UK) produces cholestenone and hydrogen peroxidase. The hydrogen peroxide is then used as an oxidising agent in a colorimetric assay.

The cholesterol content of gall stones was measured by crushing the dried stones with a pestle and mortar, extracting the cholesterol in isopropanol and quantifying it as described above.

\section{PHOSPHOLIPID}

Phospholipid was assayed using an enzymatic method first described by Takayama ${ }^{34}$ and modified by Qureshi et al. ${ }^{35}$ Dual enzymatic digestion of bile with phospholipase and choline oxidase (Wako Chemical Company, Eastleigh, UK) leads to the release of hydrogen peroxide which is used as the oxidant in a colorimetric assay.

\section{BILE ACIDS}

The total bile acid content of gall bladder bile was measured using an enzymatic method in which 3- $\alpha$-hydroxy-steroid dehydrogenase (Sigma UK) is used to oxidise bile acids allowing reduction of nicotinamide adenine dinucleotide to nicotinamide adenine dinucleotide hydride (personal communication).

\section{CHOLESTEROL SATURATION}

The cholesterol saturation was determined by calculating the actual percentage of cholesterol in bile and dividing it by the theoretical maximal cholesterol solubility. ${ }^{36}$

\section{CALCIUM}

The total calcium of gall bladder bile was measured using atomic absorption spectrophotometry. ${ }^{37}$

\section{CHOLESTEROL NUCLEATION TIME}

Nucleation time was measured in the so called isotropic 'micellar' phase obtained by centrifugation of bile for one hour at $200000 \mathrm{~g}$. After centrifugation samples were examined for the presence of cholesterol crystals then incubated at

TABLE I Ten patients in the aspirin treated group were withdrawn from the study as compared with eight in the control group. Reasons for withdrawal are indicted together with the numbers of patients in each category

\begin{tabular}{|c|c|c|c|}
\hline \multicolumn{3}{|c|}{$\begin{array}{c}\text { Patients withdrawn from trial } \\
\text { Group }-1 \\
\text { Aspirin }\end{array}$} & \multirow{2}{*}{$\begin{array}{l}\text { Group-2 } \\
\text { Control }\end{array}$} \\
\hline 7 Women - & $\begin{array}{l}3 \text { mucocele } \\
2 \text { fibrosis } \\
1 \text { adenocarcinoma } \\
1 \text { aspirin withdrawn }\end{array}$ & $\begin{array}{l}3 \text { Women - } \\
5 \text { Men - }\end{array}$ & \\
\hline 3 Men - & 3 aspirin withdrawn & & $\begin{array}{l}1 \text { oedema } \\
1 \text { infected }\end{array}$ \\
\hline
\end{tabular}


TABLE II Age, sex, symptom duration and histology in the two groups. The severity of cholecystitis was graded independently by a pathologist

\begin{tabular}{|c|c|c|}
\hline Patient age, sex, & $\begin{array}{l}\text { 2ptoms and histology } \\
\text { Group - I Aspirin }\end{array}$ & Group - 2 Control \\
\hline $\begin{array}{l}\text { n } \\
\text { Age (yr) } \\
\text { F: M } \\
\text { Symptoms (yr) } \\
\text { Histology }\end{array}$ & $\begin{array}{l}27 \\
54 \cdot 4 \text { (range 21-84) } \\
21: 6 \\
2 \cdot 7(\text { SD } 2 \cdot 7) \\
\text { normal }-3 \\
\text { mild chronic } \\
\text { cholecystitis }-14 \\
\text { moderate chronic } \\
\text { cholecystitis }-7\end{array}$ & $\begin{array}{l}28 \\
52 \cdot 0(\text { range } 23-74) \\
26: 2 \\
2 \cdot 9(\mathrm{SD} 2 \cdot 5) \\
\text { normal }-2 \\
\text { mild chronic } \\
\text { cholecystitis - } 13 \\
\text { moderate chronic } \\
\text { cholecystitis }-5\end{array}$ \\
\hline
\end{tabular}

$37^{\circ} \mathrm{C}$ under nitrogen. Further aliquots of this isotropic phase were removed daily and examined with polarizing light microscopy (Leitz, Wetzlar) to look for cholesterol crystals. ${ }^{38}$

\section{STATISTICAL ANALYSIS}

Data were compared visually using histograms and statistically using the Francia Shapiro W' test to test for normality. Where data were found to be normally distributed, the unpaired $t$ test was used to compare the two patient groups. For those data which were not normally distributed, log transformations was utilised to obtain a normal distribution and the unpaired $t$ test was then used to compare the two groups.

\section{Results}

Of 73 patients randomised, 18 were withdrawn from the study (Table I). Patients who had fibrotic oedematous or acutely infected gall bladders were withdrawn from the study because it was not possible to conduct explant culture.

Of the 55 patients who were suitable for further study, 27 were randomised to the aspirin treated group and 28 to the control group. The male to female ratio, mean age and mean duration of symptoms were similar in the two groups (Table II). Gall bladder histology was also comparable in both groups.

\section{MUCUS GYLCOPROTEIN SYNTHESIS BY GALL \\ BLADDER MUCOSA}

Gall bladder mucus biosynthesis, as measured by ${ }^{3} \mathrm{H}$-glucosamine incorporation, was significantly less in aspirin treated patients than in the untreated controls. Gall bladder explants from controls incorporated a mean of $2008 \mathrm{fmol} / \mathrm{g}$ wet weight (SD 892) of ${ }^{3} \mathrm{H}$-glucosamine as compared with $1347 \mathrm{fmol} / \mathrm{g}$ wet weight (SD 722) in aspirin treated patients $(p<0.005,95 \%$ confidence interval for the difference 222 to 1100 , unpaired $t$ test), (Figure). Incorporation of ${ }^{3} \mathrm{H}$-glucosamine

TABLE III Gall bladder bile composition and gall stone composition in the two groups

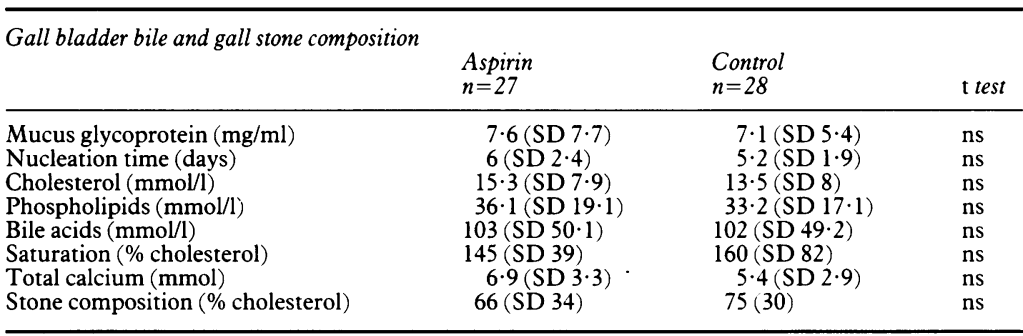

into mucosal explants linear over 24 hours. Controls containing liquid nitrogen killed tissue incorporated a maximum of $3 \mathrm{fmol} / \mathrm{g}$ wet weight of ${ }^{3} \mathrm{H}$-glucosamine.

\section{GALL BLADDER BILE COMPOSITION}

Both gall bladder bile mucus concentration and cholesterol nucleation time were similar in the two groups (Table III). Cholesterol saturation, calcium concentration and stone composition were also similar in the two groups (Table III).

\section{SIDE EFFECTS AND COMPLICATIONS}

There was no postoperative morbidity in the control group. Two patients in the aspirin treated group had complications. One had evidence of a prolonged clotting time postoperatively and her haemoglobin fell from $12.5 \mathrm{~g} / \mathrm{dl}$ to $10 \mathrm{~g} / \mathrm{dl}$ on the first postoperative day. No transfusion was needed and the patient showed no clinical signs of blood loss. The second had a small melaena after two days of aspirin treatment and he was therefore withdrawn from the study.

\section{Discussion}

This study shows that low dose aspirin significantly inhibits mucus sýnthesis in the human gall bladder in vivo. Our earlier work ${ }^{+}$has shown that aspirin will inhibit human gall bladder mucus glycoprotein biosynthesis in vitro and this present study shows that this inhibition occurs in vivo. This is not, however, accompanied by significant changes in soluble mucin content in gall bladder bile or gall bladder bile composition. This may be as a result of short term treatment (seven days), or because of the low dose of aspirin chosen for this study.

What is clear is that the mucus biosynthetic machinery of the gall bladder mucosa has been reduced by short term aspirin treatment. Over a longer period of time this would be expected to establish a decreased level of mucus production by the gall bladder and thus diminish its potential as a nucleating agent. Mucus has been shown to be a nucleating agent in vitro ${ }^{39+0}$ and in vivo increased mucus glycoprotein synthesis and secretion antedates gall stone formation in the rabbit ${ }^{+1}$ and the prairie dog. ${ }^{1}$ Aspirin inhibits mucus synthesis and secretion and prevents gall stones in the prairie dog. ${ }^{2}$ Our results here show that in man aspirin has similar actions on gall bladder mucus glycoprotein biosynthesis.

Stone reccurrence is a major problem with all forms of gall stone treatment which leave the gall bladder in situ. Ruppin et $a l^{16}$ followed 54 patients successfully treated with oral bile acids for a mean of 23 months and found that $25(46 \%)$ suffered recurrent stones. O'Donnell et al ${ }^{17}$ found a similar recurrence rate in their study of 40 patients, $50 \%$ of whom had a recurrence within five years. In a longer term study, Villanova $e t$ $a l^{1+}$ found a $61 \%$ gall stone recurrence rate at 11 years in 86 patients. Gall stone recurrence has also been studied in patients after percutaneous cholecystolithotomy and shock wave lithotripsy although the length of follow up is much shorter than in post dissolution studies. Eight months 


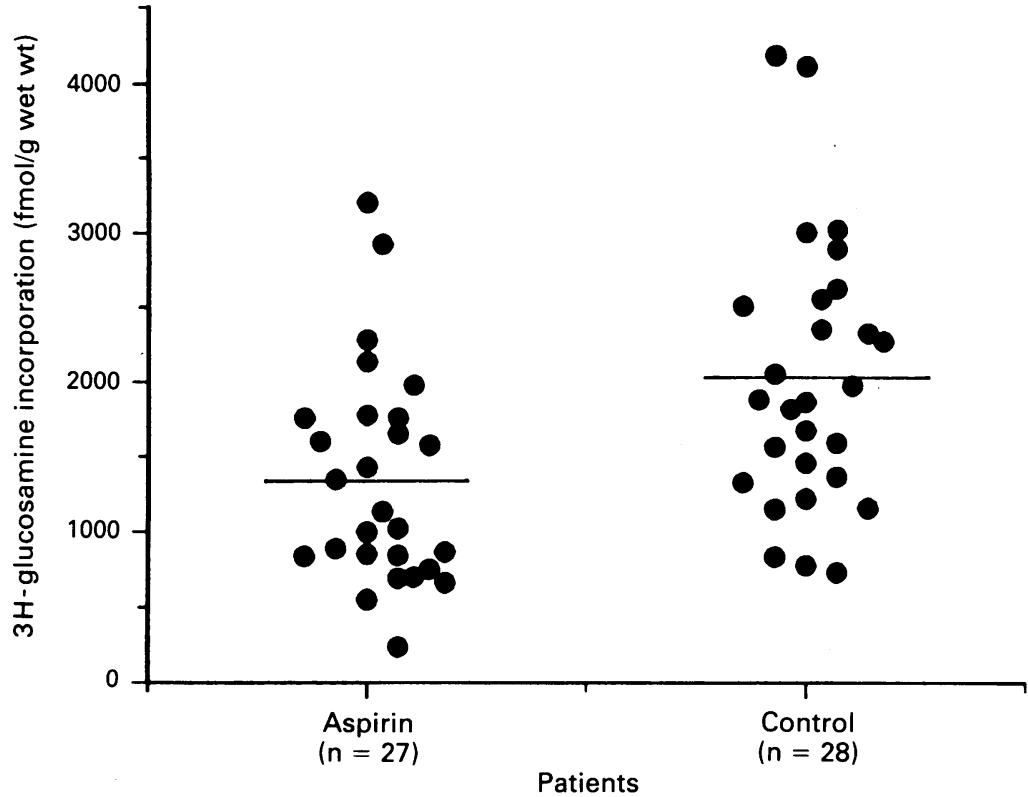

Figure: Mucus glycoprotein biosynthesis as measured by ${ }^{3} \mathrm{H}$-glucosamine incorporation over 24 hours and treatment with papain for 72 hours followed by exhaustive dialysis (144 hours). Each patient is represented by a dot and the mean of each group by a horizontal line. Mean incorporation in aspirin treated patients with 1347 fmol/g wet weight (SD 722) as compared with 2008 (SD 892) in controls; $p<0 \cdot 005$, unpaired test, $95 \%$ confidence interval for the difference 222-1100. role for the drug in the prevention of gall stones among high risk groups. This work was funded by the Newcastle Health Authority Newcastle upon Tyne William Edmund Harker Bequest. Our thanks to several surgeons in the Northern Region who provided patients for the study and in particular Mr A Gunn who helped patients for the study and in particular Mr A Gunn who
with the administration of the trial in Northumberland.

1 Lee SP, LaMont JT, Carey MC. Role of gallbladder mucus hypersecretion in the evolution of cholesterol gallstones. $\mathscr{F}$ Clin Invest 1981; 67: 1712-3.

2 Lee SP, Carey MC, LaMont JT. Aspirin prevention of cholesterol gallstone formation in prairie dogs. Science 1981 211: 1429-31.

3 Hood K, Gleeson D, Ruppin DC, Dowling RH. Prevention of gallstone recurrence by non-steroidal anti-inflammatory drugs Lancet 1989; 1223-5.

4 Rhodes M, Coan RM, Lennard TWJ, Allen A. Inhibition of mucus synthesis by aspirin in the human gallbladder. Gut 1990; 31: A1215

5 Danzinger RG, Hofmann AF, Schoenfield LJ, Thistle JL. Dissolution of cholesterol gallstones by chenodeoxycholic acid. $N$ Eng f Med 1972; 286: 1-8.

6 Bell GD, Whitney B, Dowling RH. Gallstone dissolution in man using chenodeoxycholic acid. Lancet 1972; ii: 1213-6.

7 Fromm H. Gallstone dissolution therapy. Current status and future prospects. Gastroenterology 1986; 91: 1560-7.

8 Thistle JL, et al. Dissolution of cholestrol gallbladder stones by MTBE administered by percutaneous transhepatic by MTBE administered by percutane

9 Sauerbruch T, Delius M, Paumgartner G, et al. Fragmentation of gallstones by extracorporeal shock waves. $N$ Engl $\mathcal{F}$ Med 1986; 314: 818-22.

10 Sackmann M, Delius M, Sauerbruch T, et al. Shock wave lithotripsy of gallbladder stones. The first 175 patients. $N$ Engl F Med 1988; 318: 393-7.

11 Hood KA, Keightley A, Dowling RH, Dick JA, Mallinson CN. Piezo-ceramic lithotripsy of gallbladder stones: initial experience in 38 patients. Lancet 1988; i: $1322-4$.

follow up in 53 patients who underwent successful percutaneous removal of their gall stones revealed recurrent stones in five ${ }^{18}$ whilst the same duration of follow up in 49 patients who underwent shock wave lithotripsy also showed five to have recurrent stones. ${ }^{19}$

It has been suggested that recurrent stones are amenable to repeat dissolution therapy ${ }^{+2}$ but experience with this approach is limited. One possible way of preventing gall stone recurrence is the use of long term, low dose aspirin. There is extensive evidence that aspirin prevents gall stone formation in the prairie dog through its inhibition of mucus synthesis and secretion. ${ }^{2}$ Broomfield et $a l^{26}$ studied the effects of aspirin $(1200 \mathrm{mg} / \mathrm{day})$ and urosodeoxycholic acid (1300 $\mathrm{mg} /$ day) on duodenal bile composition and on microcrystal, microstone and gall stone formation in 53 patients dieting to lose weight. Patients taking aspirin or ursodeoxycholic acid had significantly lower bile glycoprotein concentrations when compared with the placebo group and both had a reduced incidence of gall stone, microstone and cholesterol crystal formation. Hood $e t a l^{3}$ found that gall stone recurrence after dissolution was significantly less in patients taking long term non-steroidal anti inflammatory agents, a result consistent with the work of Broomfield.

Our study has shown inhibition of gall bladder mucin biosynthesis using aspirin at a dose of 300 $\mathrm{mg} /$ day. At this dose we have failed to show significant prolongation of cholesterol nucleation time. Longterm treatment with aspirin at a dose of $300 \mathrm{mg} /$ day has been shown to be safe in asymptomatic subjects who took part in The Physicians Health Study ${ }^{+3}$ and the UK TIA study. ${ }^{++}$If future studies show prolongation of cholesterol nucleation time as a consequence of longterm treatment with aspirin at a dose between $300 \mathrm{mg} /$ day and $1200 \mathrm{mg} /$ day, there might be a
12 Kerlan Jnr RK, LaBerge JM, Ring EJ. Percutaneous cholecystolithotomy: preliminary experience.Radiolog 1985; 157: 653-6.

13 Kellet MJ, Wickham JEA, Russell RCG. Percutaneous cholecystolithotomy. BMF 1988; 296: 453-5.

14 Villanova $N$, et al. Gallstone recurrence after successful ora bile acid treatment. Gastroenterology 1989; 97: 726-31.

15 Lanzini A, Jazrawi RP, Kupfer RM, Maudgal DP, Joseph AE Northfield TC. Gallstone recurrence after medical dissolution. An overestimated threat? F Hepatol 1986; 3 $241-6$.

16 Ruppin DC, Dowling RH. Is recurrence inevitable after gallstone dissolution by bile acid treatment? Lancet 1982 $181-5$.

17 O'Donnell LDH, Heaton KW. Recurrence and re-recurrence of gallstones after medical solution: long term follow up. Gut 1988; 29: 655-8.

18 Cheslyn-Curtis S, Donald J, Ainley C, Lees WR, Russel RCG. Gallstone recurrence following percut
lithotomy. Brf Surg 1990; 77: 1423 .

19 Carey MC. Formation of cholesterol gallstones: the new paradigms. Trends in bile acid research. London: Kluwer Academic, 1988; 259-81

20 Holzbach RT, Marsh M, Olszewski M, Holan K. Cholestero solubility in bile: evidence that supersaturated bile is frequent in healthy man. $\mathcal{F}$ Clin Invest 1973; 52: 1467-79.

21 LaMorte W, Schoetz D, Birkitt D, Williams L. The role of the Gastroenterology 1979; 77: 580-92

22 Forgacs IC, Maisey MN, Murphy GM, Dowling RH. Influence of gallstones and ursodeoxycholic acid therapy on gallbladder emptying. Gastroenterology 1984; 87: 299-307.

23 Doty JE, Pitt HA, Kuckenbecker SL, et al. The role of gallbladder mucus in the pathogenesis of cholesterol gallgallbladder mucus in the pathogen
stones. Am f Surg 1983; 145: 54-61.

24 LaMorte WW, LaMont JT, Hale W, Booker ML, Scott TE, Turner B. Gallbladder prostaglandins and lysophospholipids as mediators of mucin secretion during cholelithiasis. Am $\mathcal{F}$ Physiol 1986; 251: G701-9.

25 Carey MC, Cahalane MJ. Whither biliary sludge? Gastroenterology 1988; 95: 508-23.

26 Broomfield PH, Chopra R, Sheinbaum RC, et al. The effects of ursodeoxycholic acid and aspirin and the formation of lithogenic bile and gallstones during loss of weight. $N E n g l f$ Med 1988; 319: 1567-72.

27 Hunter AC, Allen A, Garner A. Studies on mucus biosynthesis in the gastrointestinal tact. In: Chantler E, Ratcliffe NA eds. Mucus and related topics. 1989. Society for Experimental Biology. 1989; London \& Sydney.

28 Allen A. Gastrointestinal mucus. Handbook of physiologv. Vol 111. Bethesda, USA: American Physiological Society, 1989, 111. Bethes

29 Pearson JP, Kaura R, Taylor W, Allen A. The composition and polymeric structure of mucus glycoprotein from human gallbladder bile. Biochim Biophys Acta 1982; 706: 221-8.

30 Thornton DJ, Holmes DF, Sheehan JK, Carlstedt I Quantitation of mucus glycoproteins blotted onto nitrocellulose membranes. Anal Biochem 1989; 182: 160-4.

31 Mangle M, Allen A. A colorimetric assay for glycoprotein based on the periodic acid/Schiff reaction. Biochem Soc Tran 1978; 6: 607-9. Gallstone recurrence following percutaneous cholecystogallbladder in the pathogenesis of cholesterol gallstones. 
32 Roda A, et al. Enzymatic determination of cholesterol in bile. Clin Chim Acta 1975; 64: 337-41.

33 Bolton $\mathrm{CH}$, Nicholls JS, Heaton $\mathrm{KW}$. Estimation of cholesterol in bile: an assessment of an enzymatic method Clin Chim Acta 1980; 105: 225-30.

34 Takayama $M$, Itoh S, Nagasaki T, Tanimizu I. A new enzymatic method for determination of serum choline containing phospholipids. Clin Chim Acta 1977; 79: 93-8.

35 Qureshi MY, Murphy GM, Dowling RH. The enzymatic determination of total phospholipids in bile and bile rich duodenal aspirates. Clin Chim Acta 1980; 105: 407-10.

36 Thomas PJ, Hofmann AF. A simple calculation of the lithogenic index of bile: expressing biliary lipid composition on retangular coordinates. Gastroenterology 1973; 65:698700

37 Willis JB. The determination of metals in blood serum by atomic absorption spectroscopy-1 (Calcium). Spectrochim Acta 1960; 16: 259 .

38 Holan KR, Holzbach RT, Hermann RE, Cooperman AM, Claffet NJ. Nucleation time: a key factor in the pathogenesis of cholesterol gallstone disease. Gastroenterology 1979; 77 : 611-7.

39 Levy PF, Smith BF, LaMont JT. Human gallbladder mucin accelerates nucleation in artifical bile. Gastroenterology 1984 87: $270-5$

40 Gallinger S, Taylor RD, Harvey PRC, Pertrunka CN, Strasberg SM. Effect of mucous glycoprotein on nucleation time in human bile. Gastroenterology 1985; 89: 648-58.

41 Freston JW, Bouchier IAD, Newman J. Biliary mucous substances in dihydrocholesterol-induced cholelithiasis. Gastroenterology 1969; 57: 670-8.

42 Hofmann AF. Bile, bile acids and gallstones: will new knowledge bring new power? Am 7 Radiol $1988 ; 151$ : 5-12.

43 Steering Committee of the Physicians Health Study Research Group. Preliminary report: Finding from the aspirin component from the ongoing Physicians Health Study. $N$ Engl f Med 1988; 318: 262-4.

44 UK-TIA Study Group. United Kingdom transient ischaemic attack (UK-TIA) aspirin trial: interim results. $B M \mathcal{F} 1988$; 246: $316-20$ 